\title{
DEMENTIS. UN DIBUJO QUE SE DIO CUENTA ${ }^{1}$
}

\author{
DEMENTIS. A DRAWING THAT REALIZED
}

\author{
Lic. Ivan Maurial Chávez² \\ Dra. Rosa Carrasco Ligarda ${ }^{3}$
}

\section{RESUMEN}

El autor del libro "Dementis, un dibujo que se dio cuenta", relata sus experiencias centrales en torno a su personaje. Nos propone a Dementis como una figura que resume elementos clave para comprender lo esencial del humano: su capacidad para reconstruir su propia trama y su capacidad para tomar distancia de sí mismo a través del sentido del humor. Dementis incursiona en el tema psicoterapéutico como imagen representativa del hombre que a pesar del sufrimiento rompe creativamente con la rigidez de los afectos. Rosa Carrasco realiza un profundo análisis lingüístico y de contenido de la obra que sitúa a Dementis como un libro rico en significados, comparándolo con personajes importantes de la literatura universal.

\section{Palabras clave}

Dementis, dibujo, mundo corazón, Espléndida

\section{ABSTRACT}

The author of "Dementis, a drawing that realized," tells his central experiences around the character. He proposes Dementis as a figure that summarizes the key elements to understand the essential of human: its ability to rebuild their own plot and its ability to take distance itself through sense of humor. Dementis enter into the psychotherapeutic topic as the representative image of the man who in spite of suffering makes a creatively breaks with the rigidity of the affections. Rosa Carrasco performs a deep linguistic analysis and content of the work that places Dementis like a book rich in meanings, comparing with important characters of the world literature.

\section{Keywords}

Dementis, drawing, earth, heart, splendid

\section{A MODO DE INTRODUCCIÓN Por Iván Maurial}

Hablar acerca de Dementis significa para mí reunir las experiencias más valiosas de $\mathrm{mi}$ vida. Es un pequeño libro que no abunda en letras como en los "Ejercicios Espirituales" de Iñigo López de Loyola. La obra del jesuita no es tanto para leer que para poner en práctica. La comunicación íntima con el Creador requiere ejercicio de la voluntad personal que no puede dejar de amar cuando lo presiente. Yo soy menos riguroso y más mundano en mi pretensión de hablar sobre lo mejor del hombre. Dementis es un diálogo entre dibujo y dibujante. Un dibujante con la joroba del miedo y necesitado de su dibujo para calmar una pena del corazón. Además, él

1 Maurial, I. (2011) Dementis, un dibujo que se dio cuenta. Lima: GRP. SAC.

2 Licenciado en Psicología. Docente de Estructura y Evaluación de la Personalidad en la Facultad de Psicología de la Universidad Femenina del Sagrado Corazón. Docente de Ética en la Facultad de Medicina de la Universidad Peruana Cayetano Heredia.rmaurial@yahoo.es

3 Doctora en Filología por la Universidad Complutense de Madrid. Tiene tres maestrías. Directora del Centro de Investigación de la Universidad Femenina del Sagrado Corazón.Docente ordinaria de la UNIFÉ. rcarrasco@unife.edu.pe 
era un dibujo que dejó de serlo para quedarse atrapado en el limbo de las aspiraciones más humanas. Conoció la libertad, esa que muchos psicólogos niegan en el nombre de la ciencia.

Dementis nos habló sobre todo de amor. Lo tenía muy claro. Cuando no se está en el mundo tanto rato y se tiene el corazón de papel, uno suele darse cuenta, casi por instinto, de lo importante. Y no hay teoría psicológica que pueda expresar tanta razón del sentimiento como sí lo puede hacer una mirada de amor y de compasión. Dementis era nuevo en este planeta y miraba con ternura este mundo de acostumbrados. Amó sin necesidad de tocar y solo tenía dos bracitos de papel para abrazar a Espléndida. Con el breve tiempo que tuvo y a pesar de su desencanto adolescente, aprendió a abrazar el mundo de los humanos, de los buenos y de los mediocres. El de los inseguros que se creían poca cosa y el de los que se creían perfectos a causa de su inseguridad.

El libro Dementis no es tanto para leer sino para contemplar. La sonrisa es inevitable cuando se ve al Homo Sapiens Sapiens junto a Homo Demens Trascendentalis. La historia hubiera sido muy desabrida sin la cultura Dementis y era necesario rescribirla. Así lo hacemos en la psicoterapia. La terapeia consiste en reconstruir tramas vitales y el quid de la misma está en salir de la rigidez del afecto que nos vuelve esclerotímicos y perfectos. Paradójicamente, las escuelas de psicoterapia, cada una con su orientación particular, suelen tener estructuras algo rígidas. La historia dementiana y el personaje Dementis representan ese esfuerzo por no mutilar lo humano en el afán de afirmar nuestras posturas acerca de la vida y de la salud mental.

Dementis está sufriendo pero no tiene la rigidez del corazón que, por el contrario, mantiene quien lo considera loco (equivocado, iluso, patológico). Es un personaje que experimenta victoria y derrota pero estas se han quedado atrás. Él se ha dado cuenta de lo importante: que las grandes batallas se libran en el corazón. Dementis se ha dado cuenta, como el Principito de Saint Exupéry, que el mundo está demasiado acostumbrado a sus intereses y pleitos. Las normas han asfixiado su espontaneidad y sus cuerpos quedaron falsamente derechos y notoriamente rígidos.

Pero Dementis ya había visto este circo en el mundo de los cuentos. Los humanos eran parecidos a los dibujos incrédulos que negaban, en el nombre de la ciencia-dibujo, nuestro mundo tridimensional. Sabían mucho aquellos dibujos del cuento, pero eran analfabetos del corazón. Y Dementis amaba a Espléndida en lo más profundo del alma y por eso sentía compasión por ellos. Espléndida no lo quería. Pero a Dementis le bastaba pensar en ella. "No era necesario tocar para amar", me decía. Para quedar iluminado no es necesario tocar el Sol. No te faltaba razón Dementis: el mundo merecía compasión porque allí un día estuvo Espléndida.

\section{ALLÁ VIVE ESPLÉNDIDA}

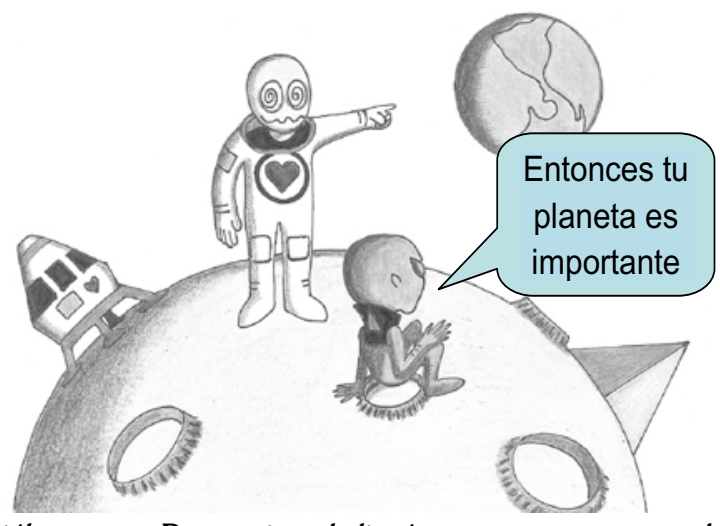

Diálogo entre Dementis y el alienígena que no comprende del todo pero que intuye algo del amor humano. Dibujo de la página 100 de "Dementis, un dibujo que se dio cuenta".

Dementis vino y se fue rápido, su vidita de papel sin embargo, me dijo mucho. Trazarlo no fue difícil, pintarlo fue motivo de gozo. Pero su vida de cuento no fue suficiente. La prehistoria humana debía ser rescrita, los antropólogos olvidaron a Homo demens y los historiadores pasaron por alto la cultura dementis. Y Dementis debía dejar de ser dibujo y ser como nosotros. Le faltan orejas y nariz, no estoy seguro si llegó a ser humano, pero Dementis, precisamente por su presentación imperfecta y atolondrada, reúne las condiciones para simbolizar lo central del fenómeno humano: el hombre imperfecto, cambiante, lleno de errores y correcciones para disimular. Es el 
humano que a pesar de su historia hecha de guerra y dolor, sabe tomar distancia de su locura y se ríe de sí mismo.

Presenté públicamente a Dementis en Setiembre de 2011 en el auditorio de la Universidad Femenina del Sagrado Corazón. Luego en el Instituto Raúl Porras Barrenechea de Miraflores. En las dos ocasiones conté con el apoyo de dos colegas y amigos que tuvieron a bien presentar a Dementis. Entre ellos estuvo Rosa Carrasco Ligarda, quien hizo un extraordinario análisis lingüístico y de contenido del libro. Tuve mucha suerte de conocerla, pues dio de su tiempo para escucharme en momentos difíciles y me enseñó nuevas maneras de ver mejor la realidad. Ella ha tenido la bondad de entregarme el texto que expuso cuando, junto a Alessandro Caviglia, presentamos a Dementis. El escrito lo incluyo a continuación.

\section{UN DIBUJO QUE SE DIO CUENTA Por Rosa Carrasco}

El libro Dementis de Iván Maurial desde el título se presenta como una propuesta particular que en consonancia con los textos literarios, al decir de Octavio Paz, participa de 'la otra orilla', lo cual es signo de la libertad de un autor. Libertad que se revela en la creación a través de un lenguaje capaz de transgredir los cánones estereotipados y registros lingüísticos consensuados propios de habla cotidiana; además, se constata la habilidad del autor para desarrollar una trama que resulta sui géneris por la novedad del contexto en el cual se desenvuelve. Esos aspectos se perfilan en Dementis con una aparente sencillez, pero entrañan una gran densidad semántica. Veamos algunas coordenadas en las cuales se sustenta esta afirmación.

Dentro del plano del lenguaje, el apelativo Dementis del protagonista, es una propuesta léxica que se clasificaría como un latinismo por su aparente filiación con una voz propia del latín; sin embargo, se trata de una palabra creada a partir del lexema castellano 'demen' de 'demente', al cual se le ha añadido el sufijo genitivo 'tis' que existe en latín, lo cual permitiría precisar una filiación etimológica cuyo significado sería 'la demencia que posee', y ¿quién es el poseedor de esa demencia?, la respuesta es Dementis. Por ende, el apelativo 'Dementis' resulta de una trasgresión de las estructuras del latín, primero porque el genitivo se refiere a un objeto poseído que no se menciona y segundo porque es una voz nueva, diríamos un neologismo, que entre los sustantivos es un nombre común y no un nombre propio. Sin embargo, lejos de representar un aspecto negativo, irónicamente introduce en un universo que reescribe la historia de la humanidad a partir de nuevas fuentes y proporciona datos fidedignos que explican la condición humana, y esto hay que agradecer al autor ya que presenta una explicación bastante completa que nos permitirá entendernos y entender nuestra cultura.

El valor lingüístico de la obra se incrementa dado que desde el título se contribuye a enriquecer el lenguaje y a dotarlo de nuevos aportes expresiones que preveo serán esenciales en un futuro próximo. Extrapolando ese indicador a toda la obra, el tratamiento lingüístico desde el título del libro permite tomar una distancia irónica con la realidad porque prefigura un carácter lúdico y es indicador de diversos recursos lingüísticos que permiten comprender la trascendencia de la creación de la palabra 'dementis' en la obra, ya que crea su propio campo semántico. Por ejemplo, da lugar al sustantivo complejo 'Homo demens' que se refiere a un tipo particular de humanos extinguidos, pero no sabemos cómo Dementis pertenece a la cultura de los demens, cultura que dejó vestigios en oriente como un muro que data del siglo IX antes de Cristo, en el cual se puede leer un gentilicio "Dementakis sabioks" que seguramente motivará mayores investigaciones en la comunidad académica. También se menciona un adjetivo formado por derivación 'dementiana' en el sintagma 'reflexión dementiana' que alude al pensamiento analítico dentro de la 'cultura dementis' o la 'mitología dementiana', la complejidad se suma dado que 'dementis' pasa a ser un adjetivo calificativo, además, se habla de los 'dementis' como gentilicio, para aludir a los naturales y originarios de 
ese pueblo, lo cual es índice de esa súper cultura diminuta. Todos los indicios son signos de la antigüedad, de los ancestros y de su importancia. Sin embargo, el personaje Dementis aparece ex nihilo, es decir de la nada, y ya mayorcito llega a la Tierra, algo así como un extraterrestre. Pero sigamos analizando el rico acervo lingüístico, se encuentra variantes de una palabra para evidenciar un abanico de caracteres diferenciadores, por ejemplo para referirse a tipos humanos, como 'Religiosus entumecido', 'Religiosus entusiasmado' y 'Falso religiosus'. Además hay expresiones que aluden a tipos particulares diferenciadores como Homo patiens (hombre doliente) o Mentalis (pensador) y apelativos irónicos como Pontificia Universidad de Chuchito $y$ Alrededores, cuya sigla es (PUCHA) o el Servicio Higiénico de Inteligencia, cuya sigla es (SHIN) que traen ecos de apelativos de prestigiosas instituciones que existen en nuestro entorno. Esta es una pequeña muestra de los numerosos recursos verbales que se aplican en la obra.

Un punto que avala la veracidad de las fuentes presentadas al inicio de la obra, bajo el título "La cultura dementis" es la construcción del texto con notas a pie de página aplicados solo en esa parte, ya que después desaparecen. Ese recurso también fue aplicado por Jorge Luis Borges en algunos de sus relatos como "El jardín de senderos que se bifurcan". Se trata de una técnica que emula el texto histórico o la investigación formal, dado que en el plano de la ficción todas las posibilidades son factibles y no requeriría de ese recurso. Sin embargo, tienen un papel fundamental ya que desrealizan la diferencia entre la verdad y la ficción, al ser así, ambos planos normalmente irreconciliables se traslapan y la ficción participa del estatuto de la realidad.

Desde un punto de vista semántico, el apelativo del personaje Dementis tiene un carácter calificativo y es clave para aproximarse a otros nombresque también representan percepciones de comportamiento o valoraciones subjetivas íntimas. Es así como San Astustín, Religiosus o Espléndida proporcionan pistas sobre el ser de los personajes. Configuran lo no dicho, lo sugerido a través de connotaciones que se complementan sutilmente con las imágenes pictóricas que los representan. Este punto es fundamental porque existe una nítida integración entre la palabra y el ícono, por lo cual resultan básicos los detalles de los dibujos que delinean el perfil de Dementis como personaje dentro de una realidad no siempre satisfactoria y compleja.

Desde una perspectiva semiótica, los dibujos hacen eco de una aprehensión que recoge el lenguaje cotidiano con el refrán "una imagen vale más que mil palabras". Este punto permite señalar que en general todos los dibujos que aparecen en el texto están delineados con plasticidad, armonía y con una gracia particular, como cuando Dementis asume el papel Dementis Marceau, nombre inspirado en Marcel Marceau el genio francés de la pantomima. Además, los dibujos presentan trazos nítidos, bordes redondeados y se evita la superposición de detalles, se seleccionan los esenciales, todo lo cual contribuye a la caracterización de los personajes y a la comprensión cabal de la circunstancia mediante una complementación entre el dibujo y el color. Al mismo tiempo, revelan un fino humor, aunque se trate de representar entidades no necesariamente gratificantes. Característica que en el intertexto, salvando las diferencias, tiene consonancia con $E l$ principito, donde también se aprecia la mirada franca y candorosa de un protagonista que descubre un universo diferente al suyo. A diferencia de ese libro, Dementis resulta de una aproximación a la génesis del universo, del protagonista y a parte de su experiencia de vida. Lo cual explica el título del libro y su centralidad en el protagonista, a semejanza del Lararillo de Tormes, apelativo del personaje que es el primer antecedente de la novela contemporánea o de Un mundo para Julius dentro de nuestro contexto.

Otro cauce intertextual es la conexión de Dementis con la literatura feérica, es decir, con la literatura maravillosa, a través de Espléndida, que como la Cenicienta y Blanca Nieves, es la dama ideal que representa un arquetipo que mueve la acción de Dementis. Además, a través de Espléndida, cuyo nombre cobra un ritmo simbólico, la obra entra 
en diálogo con el misterio del simbolismo eguriano de Simbólicas en textos como la "Niña de la lámpara azul". Dementis como el Quijote encuentran a la dama de sus sueños cuyo amor es un ideal, y ambos personajes se conmocionan y se con-mueven a emprender un viaje, coincidentemente ambos personajes se encuentran alucinados, sin embargo, tal vez sean los más cuerdos en un mundo desquiciado que es el nuestro que predica el amor pero promociona el instinto y habla de valores pero es incoherente, como en el poema "Los motivo del lobo" de Rubén Darío. De ahí dimana la propuesta en Dementis de re-crear o crear una nueva historia de la humanidad en la que se alcance su plenitud.

Si Espléndida es un personaje que solo se menciona, tiene el poder de transformar el quehacer cotidiano de Dementis, aunque es la gran ausente ya que físicamente no aparece nunca en la obra. Ella se convierte en "la dama de los sueños" de Dementis, quien al pasar de su dimensión 'plana' al mundo de los humanos, ha recibido un corazón que representa su descubrimiento de los sentimiento y de la ternura del primer amor. Si recordamos el libro de Jorge Eslava Templado nos encontramos con el diario de un adolescente, Diego, a quien también el primer amor pone de cabeza, posición en la que se lo representa en la carátula del libro, de manera semejante también se representa a Dementis en la página 40 de la obra. Ese personaje, Diego, tiene cierta analogía con Dementis por el 'loco amor', además, finalmente, ambos protagonistas no son correspondidos.

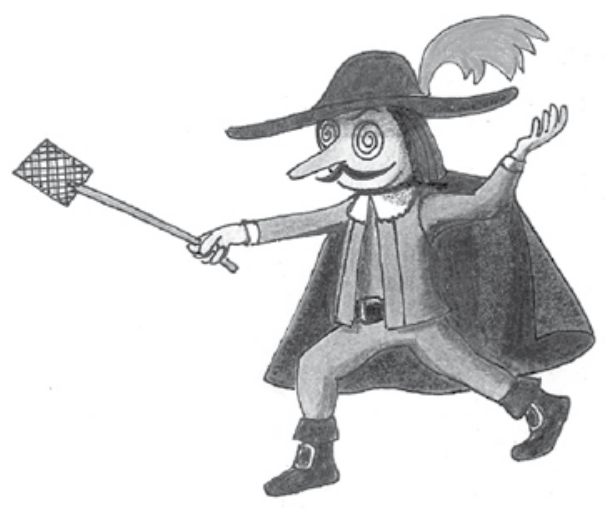

Dementis de Bergerac,. Una de las personalidades que adopta Dementis para conquistar a Espléndida, la dama de sus sueños en el dibujo de la página 53 del libro.

Desde otro plano, si se considera las connotaciones del apelativo 'Espléndida' se aprecia que corresponde a un calificativo que describe el efecto que suscita en Dementis, dentro de una técnica que se repite de presentar no nombres propios sino tipos humanos. Aunque la palabra 'Espléndida' trasciende al personaje y a la adversidad porque se convierte en el principio integrador de la escisión íntima después de la desolación y de la crisis, ya que a la manera del Quijote enamorarse de una dama es un paso, pero otro es la necesidad de, como dice el texto, "enamorarse de la vida y serle fiel.". Más allá de 'Espléndida', Dementis en su camino a Ducharmé que simbólicamente representa el limpiarse liberarse de lastres que impiden seguir adelante en la vida, descubre que dentro de la escala de valores Espléndida pasa a convertirse en un valor supremo, ya no como el amor a una mujer sino en un sentido trascendente, es lo que da sentido a la existencia, lo mismo sucede con el Quijote, él sale a enmendar entuertos y corregir el mundo en un viaje que lo transforma y le conduce a la cordura, pero contagia a Sancho de su espíritu, quien le invoca en su lecho de muerte que nuevamente salgan juntos en pos de aventuras. Desde esa perspectiva, un diálogo con Aristóteles, el gatito egresado de la "Mininet Internacional Academy University" (MIAU) que representa el pensamiento racional, le permite encontrar una clave cito "Sólo cuando el hombre olvida su propia imagen, garantiza la autenticidad de su mirada. Sólo cuando la vida del hombre se convierte en diálogo, es garantía de amor y no de invasión (...) el diálogo implica un "tú" que me llama, cada "tú" es imagen del "Tú absoluto", origen de todas las cosas, origen del amor (...) La vida, cada momento de la vida, lleva un "por quién"” p. 99.

A pesar de todo lo que he expresado, me da la impresión de no he dicho apenas nada sobre Dementis. Un dibujo que se dio cuenta porque para hacerle justicia hay numerosas perspectivas que desearía abordar. Todo lo que he mencionado son tan solo algunas pistas de lectura que como señala Bajtín son 
múltiples y tal vez la lectura equivocada sea la verdadera. Por ende, la auténtica riqueza estará en la lectura que cada uno de los presentes haga de la obra, por esto los invito a enriquecerse y deleitarse con Dementis, un personaje entrañable que no se puede olvidar.

\section{REFERENCIA}

Maurial, I. (2011) Dementis, un dibujo que se dio cuenta. Lima: GRP. SAC. 